\title{
Hospital admission rates and emergency department use in relation to glycated hemoglobin in people with diabetes mellitus: a linkage study using electronic medical record and administrative data in Ontario
}

\author{
Richard Birtwhistle MD MSc, Michael E. Green MD MPH, Eliot Frymire BEd MA, \\ Simone Dahrouge PhD, Marlo Whitehead MSc, Shahriar Khan MSc, Michelle Greiver MD MSc, \\ Richard H. Glazier MD MPH
}

Abstract

Background: The Canadian Primary Care Sentinel Surveillance Network (CPCSSN) collects extensive data on primary care patients but it currently does not gather reliable information on outcomes in other settings. The objectives of this study were to link electronic medical record (EMR) data from Ontario patients in the CPCSSN with administrative data from the Institute for Clinical Evaluative Sciences (ICES), to assess the representativeness of the CPCSSN population, and to identify people with diabetes in the CPCSSN data and describe their emergency department (ED) visits and hospital admissions over a 2-year period (2010-2012) by $\mathrm{HbA}_{1 \mathrm{c}}$ level.

Methods: We conducted a cross-sectional study linking 2014 Ontario CPCSSN data with ICES administrative data and a retrospective cohort study using the 2014 data extraction linked with data from the Ontario health care registry, hospital discharge abstracts and a database of emergency department visits. Demographics of CPCSSN patients were compared with those of the Ontario population. Patients with a CPCSSN diagnosis of diabetes were compared by $\mathrm{HbA}_{1 \mathrm{c}}$ category for $\mathrm{ED}$ visits, hospital admissions and diagnosis of diabetes-related complications.

Results: The linkage rate was $99 \%$. We identified 12358 patients with diabetes, 2356 of whom were missing data on $\mathrm{HbA}$, for a final sample of 10 002. Patients with diabetes had a mean age of 64 years. Those with a higher $\mathrm{HbA}_{1 \mathrm{c}}$ were younger, more likely to be male, had a lower income, had more comorbidities and were more likely to live in rural or suburban areas than patients with a lower $\mathrm{HbA}_{1 \mathrm{c}}$. Over the study period $31.8 \%$ of patients had 1 or more ED visits and $13.7 \%$ had a hospital admission for a diabetesrelated complication. Patients with $\mathrm{HbA}_{1 \mathrm{c}}$ greater than 8 had significantly more hospital admissions, ED visits and diabetes-related complications than patients with a lower $\mathrm{HbA}_{1 \mathrm{c}}$.

Interpretation: The linkage between EMR and administrative data was successful. In this study population, higher $\mathrm{HbA}_{1 \mathrm{c}}$ values were associated with increased ED visits and hospital admissions, with an increasing gradient as $\mathrm{HbA}_{1 \mathrm{c}}$ increased from less than $7 \%$ to greater than $8 \%$.

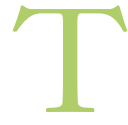
he prevalence of type 2 diabetes mellitus is increasing in North America as a result of population aging and increasing rates of obesity. ${ }^{1,2}$ Glycated hemoglobin $\left(\mathrm{HbA}_{\mathrm{cc}}\right)$ has been shown to be a good surrogate measure of diabetes control. ${ }^{3}$ There is evidence that people with higher $\mathrm{HbA}_{\mathrm{lc}}$ levels are more likely to experience longterm complications such as chronic cardiovascular disease, retinopathy and end-stage renal disease. ${ }^{4}$ As well, people with diabetes mellitus are more likely to be admitted to hospital than people without the disease. ${ }^{5}$ Electronic medical records (EMRs) are increasingly being used in research and are seen as a valuable source of data to study chronic diseases in practice. ${ }^{6}$ The value of EMR data increases when they are linked with other data sources so that process of care as well as outcomes of care can be studied.?
This study uses EMR data from patients in the Ontario network of the Canadian Primary Care Sentinel Surveillance Network (CPCSSN) linked to population-based administrative data. CPCSSN is a network of networks across Canada that extracts, transforms and stores de-identified health data from over 1.5 million patients. ${ }^{8}$ The

Competing interests: None declared.

This article has been peer reviewed.

Correspondence to: Richard Birtwhistle, richard.birtwhistle@ dfm. queensu.ca

CMAJ Open 2017. DOI:10.9778/cmajo.20170017 
extractions are done every 3 months for chronic disease surveillance, practice improvement and research. CPCSSN has validated case definitions for 8 chronic diseases including diabetes mellitus, and the case definitions in the database have been shown to have a high positive predictive value. ${ }^{9}$ The data in CPCSSN are from a representative population of people who attend primary care practices in Canada, but they are not representative of the general population. ${ }^{10}$ While CPCSSN has rich data on care delivery in the primary care setting, it currently does not have reliable information on outcomes such as mortality or health care utilization in other settings, such as hospitals or emergency departments (EDs).

The Institute for Clinical Evaluative Sciences (ICES) is a not-for-profit research institute encompassing a community of research, data and clinical experts and a secure and accessible array of Ontario's health-related data, including hospital discharges, ED attendance and health care registration. Linkage of these data to CPCSSN can fill the data gap and allow for the conduct of studies exploring health services utilization and meaningful outcomes. The objectives of this study were to link ICES and CPCSSN data, to evaluate the success of the data linkage and to identify people with diabetes in the CPCSSN data and describe their ED visits and hospital admissions over a 2 -year period by $\mathrm{HbA}_{1 \mathrm{c}}$ level.

\section{Research design and methods}

\section{Setting}

This study used data from the 4 Ontario Networks of CPCSSN, which are situated in the most populous parts of the province (London, Hamilton, Toronto and Eastern Ontario) and do not include patients from the more rural or remote parts of Ontario.

\section{Data sources}

Ontario CPCSSN data were extracted in 2014; the extraction included data from all years in the EMR chart. The CPCSSN EMR data extractions were stored as an anonymized database in a secure facility at Queen's University. The EMR patient data collected included health condition(s); risk factors such as smoking, blood pressure and body mass index (BMI); laboratory results; prescribed medication and referrals. We linked to the following ICES databases: the hospital Discharge Abstract Database (20102012), which contains patient-level data related to hospital admissions, and the National Ambulatory Care Reporting System (2010-2012), which contains data on patient visits to EDs from the Canadian Institute for Health Information (CIHI). CIHI has done extensive data quality assessments on both of these databases. We also used the 2014 Registered Persons Database, which is Ontario's health care registry.

\section{Design}

The first part of the study was cross-sectional. The Ontario CPCSSN database extracted in 2014 was sent to ICES in an encrypted file. Each patient in the database has a unique CPCSSN number that can be linked to identifiable information (health insurance number, date of birth and sex) at the practice site. Patient identifiers linked to the CPCSSN number were sent separately from each practice to ICES, which is permitted to receive and use personal health information through a special designation under Ontario's Personal Health Information Protection Act. Each patient was assigned a unique encoded ICES identifier for linkage to administrative data.

The second part of the study was a retrospective cohort study. Patients older than 18 years of age who had a CPCSSN EMR record in 2010 and a CPCSSN diagnosis of diabetes were identified and followed from 2010 to 2012 for admission to hospital or ED. The CPCSSN case detection algorithm for diabetes was as follows: a minimum of 2 occurrences of the International Classification of Diseases, 9th revision (ICD9) code for diabetes (250) in bills within 2 years; or the presence of the ICD 9 code 250 or free text indicating diabetes in the summary health profile of the chart; or the presence of hypoglycemic medication(s); or the presence of at least $1 \mathrm{HbA}_{1 \mathrm{c}}$ of $7 \%(53 \mathrm{mmol} / \mathrm{mol})$ or greater; or the presence of 2 or more fasting blood glucose results of $7 \mathrm{mmol} / \mathrm{L}$ or more within the same 12 -month period. The presence of polycystic ovarian syndrome, gestational diabetes, secondary (chemically induced) diabetes, nonspecific hyperglycemia or neonatal diabetes mellitus made the medication criteria alone insufficient for case definition. The sensitivity, specificity and positive predictive value of the algorithm against chart review were $95.6 \%$, $97.1 \%$ and $87 \%$, respectively. ${ }^{9}$ We used a look-back period of 2 years (2008-2010) to determine a diabetes diagnosis. Patients with diabetes were identified by the CPCSSN algorithm, and $\mathrm{HbA}_{1 \mathrm{c}}$ values were extracted for each patient. The Discharge Abstract Database and National Ambulatory Care Reporting System were searched for CPCSSN patients for hospital admissions, ED visits, and most responsible diagnosis by $\mathrm{HbA}_{1 \mathrm{c}}$ category (last before admission and mean over the 2 -year period). $\mathrm{HbA}_{\mathrm{cc}}$ was categorized as less than $7 \%(53 \mathrm{mmol} / \mathrm{mol}), 7.0 \%-8.0 \%$ and greater than $8 \%(64 \mathrm{mmol} / \mathrm{mol})$.

\section{Analysis}

The data linkage was done by linking the patient CPCSSN number and common patient identifiers held by ICES (health insurance number, age and sex). The proportion of those with a match was calculated. The demographics of the Ontario CPCSSN population were compared with those of the Ontario population for representativeness using measures of socioeconomic status, rurality, resource utilization and extent of chronic disease. We employed a combination of bivariate and multivariate statistical analyses using SAS software (SAS Enterprise Guide, version 6.1). We first examined patients' sociodemographic and health status characteristics by $\mathrm{HbA}_{1 \mathrm{c}}$ categories in bivariate analysis. The variables included were age, sex, income quintiles, immigrant status, rurality and an index of morbidity burden using 
Aggregated Diagnosis Groups (ADGs) from the Johns Hopkins Adjusted Clinical Groups System (www.acg.jhsph.org). We then examined the association between $\mathrm{HbA}_{\mathrm{lc}}$ categories and hospital admissions and ED visits for all causes and for acute diabetes complications (including hyperglycemia, hypoglycemia, skin and soft tissue infection or foot ulcer) and chronic complications (including cardiovascular complications, renal failure and lower extremity amputation). We tested the relationships with $\chi^{2}$ tests for categorical variables and $t$ tests for continuous variables. Finally, 2 separate logistic regression analyses were carried out to calculate the likelihood of hospital admission and ED visits, each controlling for the sociodemographic and health status characteristics of the patients. Results were expressed in terms of odds ratios (OR) with $95 \%$ confidence intervals (CIs).

\section{Ethics approval}

The study protocol was approved by both the Research Ethics Board of Queen's University and Sunnybrook Health Sciences Centre.

\section{Results}

We successfully linked $98.7 \%$ of CPCSSN patient EMR records to administrative records. In total, 115039 patients older than 18 years of age were identified in the Ontario CPCSSN data set. The characteristics of patients in the CPCSSN sample compared with those of all adult Ontario residents are shown in Table 1. CPCSSN patients were slightly older, included a higher proportion of women, were less likely to be immigrants, were more likely to live in urban areas, had a higher household income and had a higher proportion of comorbid chronic disease. There were 12358 people with a CPCSSN diagnosis of diabetes mellitus identified in the Ontario CPCSSN database linked with administrative data; 2356 patients without $\mathrm{HbA}_{\mathrm{cc}}$ values were excluded from the analysis.

The demographics of the patients with diabetes mellitus are shown in Table 2. The mean age of the sample was 63.5 years, with variation by $\mathrm{HbA}_{\mathrm{lc}}$ category: mean age was 65.7 years for patients with $\mathrm{HbA}_{1 \mathrm{c}}$ less than $7 \%(53 \mathrm{mmol} /$ mol), 64.7 years for patients with $\mathrm{HbA}_{\mathrm{lc}}$ between $7 \%$ and $8 \%$ and 58.2 years for patients with $\mathrm{HbA}_{\mathrm{lc}}$ greater than $8 \%$ (64 mmol/mol). Patients with higher $\mathrm{HbA}_{\mathrm{lc}}$ were on average younger and more likely to be male, to be in a lower income group, to have more comorbidities and to reside in rural or suburban areas than patients with $\mathrm{HbA}_{\mathrm{ic}}$ less than $7 \%$ (53 $\mathrm{mmol} / \mathrm{mol}$ ).

Patients who were missing $\mathrm{HbA}_{1 \mathrm{c}}$ measurements were compared with those who had a measurement. Patients with missing $\mathrm{HbA}_{\mathrm{cc}}$ data were younger (mean age $61 \mathrm{yr}$ v. $64 \mathrm{yr}$, $p<0.001$ ) and had fewer chronic conditions (ADG category $0,2.5 \%$ v. $0.9 \%, p<0.001$ ) (Appendix 1, available at www. cmajopen.ca/content/5/3/E557/supp1/DC1).

Over the 2 years of follow-up, $31.8 \%$ of patients had at least one ED visit and $13.7 \%$ had a hospital admission for a diabetes-related complication. The number of hospital admissions, admission diagnoses and the number of ED visits are shown in Table 3. Patients with an $\mathrm{HbA}_{1 \mathrm{c}}$ greater than $8 \%(64 \mathrm{mmol} / \mathrm{mol})$ had significantly more hospital admissions, ED visits and diabetes-related complications than patients with lower $\mathrm{HbA}_{\mathrm{cc}}$ values. Patients with $\mathrm{HbA}_{\mathrm{cc}}$ greater than $8 \%(64 \mathrm{mmol} / \mathrm{mol})$ had more ED visits for both hypoglycemia and hyperglycemia as well as hospital admissions for soft tissue infection and any acute complication. Further, patients who had $\mathrm{HbA}_{1 \mathrm{c}}$ results between $7 \%$ and $8 \%$ had higher hospital admission and ED visit rates as well as higher diabetes complication rates than those whose $\mathrm{HbA}_{\mathrm{lc}}$ was less than $7 \%$. Hospital admission rates for chronic cardiovascular conditions also increased as $\mathrm{HbA}_{\mathrm{lc}}$ increased.

After adjustment for patient sociodemographic profile and medical complexity, both ED visits (OR 1.49, 95\% CI 1.33-1.68) and hospital admissions (OR 1.51, 95\% CI 1.291.77) were significantly more likely for patients with $\mathrm{HbA}_{1 \mathrm{c}}$ values greater than $8 \%$ than for patients with $\mathrm{HbA}_{\mathrm{cc}}$ values less than 7\%; the odds of ED visits and hospital admissions for patients with $\mathrm{HbA}_{\mathrm{lc}}$ values of $7 \%-8 \%$ fell in between (Table 4, Table 5).

\section{Interpretation}

Our results showing that patients with higher $\mathrm{HbA}_{1 \mathrm{c}}$ values had more ED visits and higher hospital admission rates than patients with lower $\mathrm{HbA}_{\mathrm{lc}}$ values provide a richer understanding of the impact of diabetes control as measured by $\mathrm{HbA}_{\mathrm{lc}}$ values on health care utilization. Others have studied the relationship between $\mathrm{HbA}_{\mathrm{cc}}$ and utilization of health services. Menzin and colleagues did a retrospective analysis of a cohort of 9887 patients with diabetes in a group health plan. They found that people with diabetes with $\mathrm{HbA}_{1 \mathrm{c}}$ levels greater than 10 had a greater risk of hospital admission than those with $\mathrm{HbA}_{\mathrm{lc}}$ levels less than 7 but not than those with $\mathrm{HbA}_{\mathrm{lc}}$ values between 7 and 10. They also found that there was a higher cost of hospitalization associated with a higher $\mathrm{HbA}_{1 \mathrm{c}}$ value. ${ }^{11}$

Our study demonstrated strong associations between $\mathrm{HbA}_{\mathrm{Ic}}$ values and hospital and ED utilization at even lower $\mathrm{HbA}_{\mathrm{lc}}$ values, similar to Yu and Simmons' findings in a linkage study of 4704 people with diabetes from 18 general practices in Cambridgeshire, England. They found a nonlinear relationship between $\mathrm{HbA}_{1 \mathrm{c}}$ levels and all-cause, diabetesassociated and cardiovascular-associated hospital admissions, with a meaningful increase in risk of admission at a $\mathrm{HbA}_{1 c}$ threshold of $7.7 \% .^{12}$

There is also evidence that a reduction in $\mathrm{HbA}_{\mathrm{lc}}$ levels over time is associated with a reduction in both health care utilization and costs. ${ }^{13}$ The clear association between glycemic control and utilization of health services in Ontario has important implications for people with diabetes, practitioners and policy-makers. Increased support for educational programs to improve diabetes control may reduce the number of diabetic complications and reduce ED visits and hospital admissions in this population. 
Table 1: Comparison of Ontario patients in the Canadian Primary Care Sentinel Surveillance Network with the Ontario population

\begin{tabular}{|c|c|c|c|}
\hline \multirow[b]{2}{*}{ Characteristic } & \multicolumn{2}{|c|}{ No. $(\%)^{*}$} & \multirow[b]{2}{*}{$p$ value } \\
\hline & $\begin{array}{c}\text { CPCSSN } \\
n=115039\end{array}$ & $\begin{array}{c}\text { Ontario } \\
n=10300555\end{array}$ & \\
\hline Age in 2011, yr & & & $<0.001$ \\
\hline Mean $(95 \% \mathrm{Cl})$ & $51.03(50.93-51.13)$ & 47.66 (47.65-47.67) & \\
\hline Median (IQR) & $51(37-64)$ & $47(33-60)$ & \\
\hline \multicolumn{4}{|l|}{ Age group in 2011, yr } \\
\hline 19-34 & $24926(21.7)$ & $2784789(27.0)$ & $<0.001$ \\
\hline $35-49$ & $29998(26.1)$ & $2972495(28.9)$ & \\
\hline $50-64$ & $32341(28.1)$ & $2666329(25.9)$ & \\
\hline $65-74$ & $14740(12.8)$ & $1001007(9.7)$ & \\
\hline $75-84$ & $9531(8.3)$ & $626098(6.1)$ & \\
\hline$>85$ & $3503(3.0)$ & $249837(2.4)$ & \\
\hline Male & $46721(40.6)$ & 4991857 (48.5) & $<0.001$ \\
\hline \multicolumn{4}{|l|}{ Income quintile $\dagger$} \\
\hline 1 (lowest) & 19950 (17.3) & 1957809 (19.0) & $<0.001$ \\
\hline 2 & $19461(16.9)$ & $2032256(19.7)$ & \\
\hline 3 & $21315(18.5)$ & 2049351 (19.9) & \\
\hline 4 & $23049(20.0)$ & $2143524(20.8)$ & \\
\hline 5 (highest) & $30262(26.3)$ & $2076792(20.2)$ & \\
\hline 9 (unknown) & $1002(0.9)$ & $40823(0.4)$ & \\
\hline Immigrated to Canada in past 10 years & $8042(7.0)$ & $1143311(11.1)$ & $<0.001$ \\
\hline \multicolumn{4}{|l|}{ Rurality Index of Ontario category } \\
\hline Urban & $71894(62.5)$ & 7445676 (72.3) & $<0.001$ \\
\hline Suburban & $38641(33.6)$ & $1988531(19.3)$ & \\
\hline Rural & $3617(3.1)$ & $782232(7.6)$ & \\
\hline Missing & $887(0.8)$ & $84116(0.8)$ & \\
\hline \multicolumn{4}{|l|}{ Resource utilization band $†$} \\
\hline 0 & $4442(3.9)$ & $1002617(9.7)$ & $<0.001$ \\
\hline 1 & $5168(4.5)$ & $590414(5.7)$ & \\
\hline 2 & $18346(15.9)$ & $1730943(16.8)$ & \\
\hline 3 & $61026(53.0)$ & $5096860(49.5)$ & \\
\hline 4 & $18734(16.3)$ & $1402376(13.6)$ & \\
\hline 5 & $7323(6.4)$ & $477345(4.6)$ & \\
\hline \multicolumn{4}{|l|}{ No. of associated diagnostic groups } \\
\hline 0 & $4446(3.9)$ & $1002765(9.7)$ & $<0.001$ \\
\hline $1-4$ & $50990(44.3)$ & $4365228(42.4)$ & \\
\hline $5-9$ & $48295(42.0)$ & 3963489 (38.5) & \\
\hline$\geq 10$ & $11308(9.8)$ & $969073(9.4)$ & \\
\hline Mean $(95 \% \mathrm{Cl})$ & $5.11(5.09-5.13)$ & $4.74(4.74-4.74)$ & $<0.001$ \\
\hline Median (IQR) & $5(3-7)$ & $4(2-7)$ & \\
\hline \multicolumn{4}{|l|}{ Health condition } \\
\hline Hypertension & $34741(30.2)$ & $2717743(26.4)$ & $<0.001$ \\
\hline Diabetes & $13360(11.6)$ & $1150934(11.2)$ & $<0.001$ \\
\hline $\mathrm{CHF}$ & $3090(2.7)$ & 226162 (2.2) & $<0.001$ \\
\hline Asthma & $15499(13.5)$ & 1334846 (13.0) & $<0.001$ \\
\hline COPD & $10021(8.7)$ & 761326 (7.4) & $<0.001$ \\
\hline AMI & $2173(1.9)$ & $162566(1.6)$ & $<0.001$ \\
\hline Mental health & 27305 (23.7) & 2325243 (22.6) & $<0.001$ \\
\hline
\end{tabular}




\begin{tabular}{|c|c|c|c|c|c|c|}
\hline \multirow[b]{2}{*}{ Characteristic } & \multicolumn{3}{|c|}{$\mathrm{HbA}_{\mathrm{lc}}$, no. $(\%)^{*}$} & \multirow[b]{2}{*}{$\begin{array}{c}\text { Missing } \\
n=2356\end{array}$} & \multirow[b]{2}{*}{$\begin{array}{c}\text { Total } \\
n=12358\end{array}$} & \multirow[b]{2}{*}{$p$ value } \\
\hline & $\begin{aligned}<7 \% \\
n=5526\end{aligned}$ & $\begin{array}{c}7 \%-8 \% \\
n=2662\end{array}$ & $\begin{array}{c}>8 \% \\
n=1814\end{array}$ & & & \\
\hline \multicolumn{7}{|l|}{ Age, yr } \\
\hline Mean \pm SD & $65.68 \pm 13.13$ & $64.70 \pm 13.31$ & $58.15 \pm 13.70$ & $60.99 \pm 16.21$ & $63.47 \pm 14.17$ & $<0.001$ \\
\hline Median (IQR) & $67(57-76)$ & $66(56-74)$ & $58(49-67)$ & $62(51-73)$ & $64(54-74)$ & $<0.001$ \\
\hline \multicolumn{7}{|l|}{ Age group, yr } \\
\hline $18-39$ & $198(3.6)$ & $106(4.0)$ & $151(8.3)$ & 264 (11.2) & $719(5.8)$ & $<0.001$ \\
\hline $40-74$ & $3783(68.5)$ & 1907 (71.6) & $1441(79.4)$ & $1557(66.1)$ & 8688 (70.3) & \\
\hline$>75$ & $1545(28.0)$ & $649(24.4)$ & 222 (12.2) & $535(22.7)$ & 2951 (23.9) & \\
\hline \multicolumn{7}{|l|}{ Sex† } \\
\hline Female & $2768(50.1)$ & $1252(47.0)$ & $823(45.4)$ & $1185(50.3)$ & $6028(48.8)$ & $<0.001$ \\
\hline Male & 2758 (49.9) & $1410(53.0)$ & $991(54.6)$ & $1171(49.7)$ & $6330(51.2)$ & \\
\hline \multicolumn{7}{|l|}{ Income quintile } \\
\hline 1 (lowest) & 1064 (19.3) & $587(22.1)$ & $466(25.7)$ & 447 (19.0) & $2564(20.7)$ & $<0.001$ \\
\hline 2 & 1008 (18.2) & 506 (19.0) & 354 (19.5) & $420(17.8)$ & 2288 (18.5) & \\
\hline 3 & $1053(19.1)$ & $536(20.1)$ & 355 (19.6) & 451 (19.1) & 2395 (19.4) & \\
\hline 4 & 1101 (19.9) & 495 (18.6) & 300 (16.5) & $491(20.8)$ & 2387 (19.3) & \\
\hline 5 (highest) & $1249(22.6)$ & $517(19.4)$ & $327(18.0)$ & $460(19.5)$ & $2553(20.7)$ & \\
\hline Missing & $51(0.9)$ & $21(0.8)$ & $12(0.7)$ & $87(3.7)$ & $171(1.4)$ & \\
\hline \multicolumn{7}{|c|}{ No. of associated diagnostic groups } \\
\hline 0 & $47(0.9)$ & $22(0.8)$ & $20(1.1)$ & $59(2.5)$ & $148(1.2)$ & $<0.001$ \\
\hline $1-4$ & $1804(32.6)$ & $917(34.4)$ & $673(37.1)$ & $808(34.3)$ & $4202(34.0)$ & \\
\hline $5-9$ & $2685(48.6)$ & $1322(49.7)$ & $843(46.5)$ & $1015(43.1)$ & $5865(47.5)$ & \\
\hline$\geq 10$ & $990(17.9)$ & $401(15.1)$ & $278(15.3)$ & $474(20.1)$ & $2143(17.3)$ & \\
\hline \multicolumn{7}{|c|}{ Rurality Index of Ontario category } \\
\hline Urban (0-9) & $3283(59.4)$ & $1550(58.2)$ & $975(53.7)$ & $1353(57.4)$ & $7161(57.9)$ & $<0.001$ \\
\hline Suburban (10-39) & $2117(38.3)$ & $1044(39.2)$ & 796 (43.9) & $873(37.1)$ & $4830(39.1)$ & \\
\hline Rural ( $\geq 40)$ & $76(1.4)$ & $48(1.8)$ & $34(1.9)$ & $45(1.9)$ & $203(1.6)$ & \\
\hline Missing & $50(0.9)$ & $20(0.8)$ & $9(0.5)$ & $85(3.6)$ & $164(1.3)$ & \\
\hline
\end{tabular}

\section{Limitations}

This study has several limitations. It is a retrospective study of patients with diabetes in Ontario. It analyzed data from a sample of patients who attend family physicians and nurse practitioners in practices that use EMRs and belong to the CPCSSN sample, and the sample may not be representative. We were not able to determine the type of diabetes each patient had, nor the length of time each patient had diabetes. Nineteen percent of the patients did not have an $\mathrm{HbA}_{1 \mathrm{c}}$ measurement in our database. This may have been because they did not have the test done; more likely it was because the results were not recorded electronically in the
EMR. Some practices will only receive laboratory results on paper, which are then scanned into the EMR and not available for analysis. As well, we did not assess what other chronic diseases these patients had that influenced the likelihood of hospital admission, although ADG categories were similar between groups. ${ }^{14}$ This study does not allow causal inferences to be made, although the measurement of $\mathrm{HbA}_{\mathrm{lc}}$ levels preceded the occurrence of outcomes in this study. We were unable to account for other risk factors such as diet, physical activity, obesity, blood pressure control, lipid levels or health care utilization before the observation period. 


\section{OPEN}

\section{Research}

Table 3: Emergency department visits, hospital admissions and discharge diagnoses for Ontario patients with diabetes in the Canadian Primary Care Sentinel Surveillance Network, by $\mathrm{HbA}_{1 \mathrm{c}}$ category

\begin{tabular}{|c|c|c|c|c|c|}
\hline \multirow[b]{2}{*}{ Variable } & \multicolumn{3}{|c|}{$\mathrm{HbA}_{10}$, no. $(\%)$} & \multirow[b]{2}{*}{$\begin{array}{l}\text { Total } \\
n=10002\end{array}$} & \multirow[b]{2}{*}{$p$ value } \\
\hline & $\begin{aligned}<7 \% \\
n=5526\end{aligned}$ & $\begin{array}{l}7 \%-8 \% \\
n=2662\end{array}$ & $\begin{aligned}> & 8 \% \\
n & =1814\end{aligned}$ & & \\
\hline \multicolumn{6}{|c|}{ No. of emergency department visits } \\
\hline 0 & $3867(70.0)$ & $1812(68.1)$ & $1141(62.9)$ & $6820(68.2)$ & $<0.001$ \\
\hline 1 & $910(16.5)$ & $477(17.9)$ & $315(17.4)$ & $1702(17.0)$ & \\
\hline 2 & $359(6.5)$ & $170(6.4)$ & $160(8.8)$ & $689(6.9)$ & \\
\hline$\geq 3$ & $390(7.1)$ & $203(7.6)$ & $198(10.9)$ & $791(7.9)$ & \\
\hline \multicolumn{6}{|c|}{$\begin{array}{l}\text { No. of hospital admissions for diabetes-related } \\
\text { complications }\end{array}$} \\
\hline 0 & $4830(87.4)$ & 2267 (85.2) & $1536(84.7)$ & $8633(86.3)$ & $<0.001$ \\
\hline 1 & $503(9.1)$ & $282(10.6)$ & $168(9.3)$ & $953(9.5)$ & \\
\hline 2 & $127(2.3)$ & $61(2.3)$ & $61(3.4)$ & $249(2.5)$ & \\
\hline$\geq 3$ & $66(1.2)$ & $52(2.0)$ & $49(2.7)$ & $167(1.7)$ & \\
\hline \multicolumn{6}{|c|}{ Hyperglycemia } \\
\hline No & 5519 (99.9) & $2656(99.8)$ & $1789(98.6)$ & $9964(99.6)$ & $<0.001$ \\
\hline Yes & $7(0.1)$ & $6(0.2)$ & $25(1.4)$ & $38(0.4)$ & \\
\hline \multicolumn{6}{|c|}{ Hypoglycemia } \\
\hline No & $5512(99.7)$ & $2631(98.8)$ & $1783(98.3)$ & 9926 (99.2) & $<0.001$ \\
\hline Yes & $14(0.3)$ & $31(1.2)$ & $31(1.7)$ & $76(0.8)$ & \\
\hline \multicolumn{6}{|c|}{ Hyperglycemia and/or hypoglycemia } \\
\hline No & $5506(99.6)$ & $2625(98.6)$ & $1763(97.2)$ & 9894 (98.9) & $<0.001$ \\
\hline Yes & $20(0.4)$ & $37(1.4)$ & $51(2.8)$ & $108(1.1)$ & \\
\hline \multicolumn{6}{|c|}{ Any acute complication of diabetes } \\
\hline No & $5421(98.1)$ & $2580(96.9)$ & $1706(94.0)$ & $9707(97.1)$ & $<0.001$ \\
\hline Yes & $105(1.9)$ & $82(3.1)$ & $108(6.0)$ & $295(2.9)$ & \\
\hline \multicolumn{6}{|c|}{ Any chronic complication of diabetes* } \\
\hline No & $5411(97.9)$ & $2574(96.7)$ & $1745(96.2)$ & $9730(97.3)$ & $<0.001$ \\
\hline Yes & $115(2.1)$ & $88(3.3)$ & $69(3.8)$ & $272(2.7)$ & \\
\hline \multicolumn{6}{|c|}{ Cardiovascular condition } \\
\hline No & $5437(98.4)$ & $2589(97.3)$ & $1757(96.9)$ & $9783(97.8)$ & $<0.001$ \\
\hline Yes & $89(1.6)$ & $73(2.7)$ & $57(3.1)$ & $219(2.2)$ & \\
\hline \multicolumn{6}{|c|}{ Lower extremity amputation } \\
\hline No & $5521(99.9)$ & 2659 (99.9) & $1808(99.7)$ & 9988 (99.9) & 0.054 \\
\hline Yes & $\leq 5(0.1)$ & $\leq 5(0.1)$ & $6(0.3)$ & $14(0.1)$ & \\
\hline \multicolumn{6}{|c|}{ Skin and soft tissue infection or foot ulcer } \\
\hline No & $5439(98.4)$ & $2612(98.1)$ & $1753(96.6)$ & $9804(98.0)$ & $<0.001$ \\
\hline Yes & $87(1.6)$ & $50(1.9)$ & $61(3.4)$ & $198(2.0)$ & \\
\hline
\end{tabular}




\begin{tabular}{|c|c|}
\hline Variable & $\begin{array}{l}\text { Odds ratio } \\
(95 \% \mathrm{Cl})\end{array}$ \\
\hline \multicolumn{2}{|l|}{$\mathrm{HbA}_{1 \mathrm{c}}$ category, $\%$} \\
\hline$<7$ & 1 \\
\hline $7-8$ & $1.13(1.02-1.26)$ \\
\hline$>8$ & $1.49(1.33-1.68)$ \\
\hline \multicolumn{2}{|l|}{ Sex } \\
\hline Female & 1 \\
\hline Male & $1.02(0.93-1.11)$ \\
\hline \multicolumn{2}{|l|}{ Age group, yr } \\
\hline $18-39$ & 1 \\
\hline $40-74$ & $0.85(0.69-1.05)$ \\
\hline$>75$ & $1.25(1-1.57)$ \\
\hline \multicolumn{2}{|c|}{ No. of associated diagnostic groups } \\
\hline 0 & 1 \\
\hline $1-4$ & $0.7(0.42-1.17)$ \\
\hline $5-9$ & $1.46(0.88-2.41)$ \\
\hline$>10$ & $2.97(1.78-4.94)$ \\
\hline \multicolumn{2}{|l|}{ Income quintile } \\
\hline 1 (lowest) & 1 \\
\hline 2 & $0.87(0.76-0.99)$ \\
\hline 3 & $0.75(0.65-0.86)$ \\
\hline 4 & $0.82(0.72-0.94)$ \\
\hline 5 (highest) & $0.66(0.57-0.75)$ \\
\hline \multicolumn{2}{|l|}{ Immigration } \\
\hline Nonimmigrant & 1 \\
\hline Immigrant & $0.93(0.72-1.19)$ \\
\hline \multicolumn{2}{|c|}{ Rurality Index of Ontario category } \\
\hline Urban (0-9) & 1 \\
\hline Suburban (10-39) & 1.61 \\
\hline Rural ( $\geq 40)$ & 2.03 \\
\hline
\end{tabular}

\section{Conclusion}

This study demonstrated the successful linking of CPCSSN EMR data with administrative data in Ontario. We found that there was an increase in both ED visits and hospital admissions for all causes and for diabetes-related reasons with higher $\mathrm{HbA}_{\mathrm{lc}}$ values. Further research is required to better define the optimal $\mathrm{HbA}_{\mathrm{cc}}$ targets for patients with particular characteristics.

\section{References}

1. Lipscombe LL, Hux JE. Trends in diabetes prevalence, incidence, and mortality in Ontario, Canada 1995-2005: a population-based study. Lancet 2007;369:750-6.

2. Greiver M, Williamson T, Barber D, et al. Prevalence and epidemiology of diabetes in Canadian primary care practices: a report from the Canadian Pri-
Table 5: Estimates of adjusted risk of hospital admission for Ontario patients with diabetes in the Canadian Primary Care Sentinel Surveillance Network

\begin{tabular}{cc}
\hline & Odds ratio \\
Variable & $(95 \% \mathrm{Cl})$
\end{tabular}

$\mathrm{HbA}_{1 \mathrm{c}}$ category, \%

$<7 \quad 1$

$7-8 \quad 1.3(1.13-1.49)$

$>8 \quad 1.51(1.29-1.77)$

Sex

Female 1

Male $1.09(0.97-1.23)$

Age group, yr

$\begin{array}{lc}18-39 & 1 \\ 40-74 & 0.99(0.72-1.35) \\ \geq 75 & 2.12(1.54-2.93)\end{array}$

No. of associated diagnostic groups

\begin{tabular}{|cc|}
\hline 0 & 1 \\
\hline $1-4$ & $0.74(0.33-1.63)$ \\
\hline $5-9$ & $1.56(0.71-3.42)$ \\
\hline$\geq 10$ & $3.71(1.68-8.18)$ \\
\hline Income quintile & 1 \\
\hline 1 (lowest) & $0.99(0.83-1.19)$ \\
\hline 2 & $0.84(0.69-1.01)$ \\
\hline 3 & $0.97(0.8-1.16)$ \\
\hline 4 & $0.8(0.66-0.96)$ \\
\hline 5 (highest) & 1 \\
\hline Immigration & $1.1(0.78-1.55)$ \\
\hline Nonimmigrant & 1 \\
\hline Immigrant & $1.46(1.29-1.65)$ \\
\hline Rurality Index of Ontario category & $1.65(1.06-2.57)$ \\
\hline Urban (0-9) & \\
\hline Suburban (10-39) & \\
\hline Rural ( $\geq 40)$ & \\
\hline Note: Cl = confidence interval. & \\
\hline
\end{tabular}

mary Care Sentinel Surveillance Network. Can 7 Diabetes 2014;38:179-85.

3. Saudek CD, Derr RL, Kalyani RR. Assessing glycemia in diabetes using selfmonitoring blood glucose and hemoglobin A1c. FAMA 2006;295:1688-97.

4. The absence of a glycemic threshold for the development of long-term complications: the perspective of the Diabetes Control and Complications Trial. Diabetes 1996;45:1289-98.

5. De Berardis G, D'Ettorre A, Graziano G, et al. The burden of hospitalization related to diabetes mellitus: a population-based study. Nutr Metab Cardiovasc Dis 2012;22:605-12.

6. Birtwhistle R, Williamson T. Primary care electronic medical records: a new data source for research in Canada. CMA7 2015;187:239-40.

7. Birtwhistle R, Godwin M, Leggett JA, et al. Linking health databases for research. Can Fam Physician 2015; 61:382, e223-384.

8. Birtwhistle RV. Canadian Primary Care Sentinel Surveillance Network: a developing resource for family medicine and public health. Can Fam Physician 2011;57:1219-20.

9. Williamson T, Green ME, Birtwhistle R, et al. Validating the 8 CPCSSN case definitions for chronic disease surveillance in a primary care database of electronic health records. Ann Fam Med 2014;12:367-72. 
10. Queenan JA, Williamson T, Khan S, et al. Representativeness of patients and providers in the Canadian Primary Care Sentinel Surveillance Network: a cross-sectional study. CMAf Open 2016;4:E28-32.

11. Menzin J, Korn JR, Cohen J, et al. Relationship between glycemic control and diabetes-related hospital costs in patients with type 1 or type 2 diabetes mellitus. 7 Manag Care Pharm 2010;16:264-75.

12. Yu D, Simmons D. Relationship between HbA1c and risk of all-cause hospital admissions among people with Type 2 diabetes. Diabet Med 2013;30:1407-11.

13. Wagner EH, Sandhu N, Newton KM, et al. Effect of improved glycemic control on health care costs and utilization. FAMA 2001;285:182-9.

14. Struijs JN, Baan CA, Schellevis FG, et al. Comorbidity in patients with diabetes mellitus: impact on medical health care utilization. BMC Health Serv Res 2006;6:84.

Affiliations: Department of Family Medicine and Public Health Sciences (Birtwhistle, Green, Frymire, Whitehead, Khan), Queen's University, Kingston, Ont.; Department of Family and Community Medicine (Greiver, Glazier), University of Toronto, Toronto, Ont.; Department of Family Medicine (Dahrouge), University of Ottawa, Ottawa, Ont.; Canadian Primary Care Sentinel Surveillance Network (Birtwhistle, Green, Greiver), Kingston, Ont.; Institute for Clinical Evaluative Sciences (Birtwhistle, Green, Frymire, Dahrouge, Whitehead, Khan, Greiver, Glazier), Toronto, Ont.; North York General Hospital (Greiver), North York, Ont.; Department of Family and Community Medicine (Glazier), St. Michael's Hospital, Toronto, Ont.

Contributors: Richard Birtwhistle, Richard Glazier, Michael Green, Michelle Greiver and Simone Dahrouge designed the study, reviewed the results and contributed to writing and revising the manuscript. Eliot Frymire managed the study, reviewed the results and wrote the first draft of the manuscript. Marlo Whitehead and Shahriar Khan analyzed the data and contributed to writing and revising the manuscript. All authors reviewed and approved the final draft.

Acknowledgements: This study was supported by an Applied Health Research Question Grant from the INSPIRE Primary Health Care Research Program, which was funded through the Health Systems Research Program of the Ontario Ministry of Health and Long-Term Care (MOHLTC). Richard Birtwhistle is the chair of the Canadian Primary Care Sentinel Surveillance Network and supported by the Walter Rosser Chair in Family Medicine Research. Richard Glazier was funded as a clinician scientist in the Department of Family and Community Medicine at the University of Toronto and at St. Michael's Hospital. Michael Green is supported by the CTAQ Chair in Applied Health Economics/Health Policy. Michelle Greiver holds an investigator award from the Department of Family and Community Medicine at the University of Toronto.

Disclaimer: This study was supported by the Institute for Clinical Evaluative Sciences (ICES), which is funded by an annual grant from the Ontario Ministry of Health and Long-Term Care (MOHLTC). The opinions, results and conclusions reported in this article are those of the authors and are independent from the funding sources. No endorsement by ICES or the Ontario MOHLTC is intended or should be inferred. Parts of this material are based on data and information compiled and provided by the Canadian Institute for Health Information (CIHI). However, the analyses, conclusions, opinions and statements expressed herein are those of the authors, and not necessarily those of CIHI.

Supplemental information: For reviewer comments and the original submission of this manuscript, please see www.cmajopen.ca/content $/ 5 / 3 /$ E557/suppl/DC1. 